INDO GLOBAL JOURNAL OF

\title{
Silver Nanoparticles for Pest Control: A Bio-Nanopesticide Approach
}

\author{
Namita Soni ${ }^{*}$, Ramesh C. Dhiman \\ National Institute of Malaria Research (ICMR), Dwarka Sec-8, New Delhi-110077, India \\ Address for Correspondance: Namita Soni, namitasoni7@gmail.com
}

Keywords Silver

Nanoparticles; Pest

Control; Bio-

nanopesticide.

\begin{abstract}
Nanotechnology is an interdisciplinary science deals with the synthesis and application of nanoparticles. The synthesis of metal nanoparticles came in to light due to wide range of applications in different fields. Biosynthesis of silver nanoparticles by plant extracts is a cost effective, eco-friendly and less time consuming process where the secondary metabolites present in the plant extracts acts as reducing and stabilizing agents of silver nanoparticles. In this study, the silver nanoparticles (AgNPs) have been synthesized using the aqueous leaf extract of Castor plant. The results were obtained using a UV-Visible spectrophotometer, and the images were recorded with a transmission electron microscope (TEM). The synthesized AgNPs were spherical in shape and varied sizes. The synthesized AgNPs have been tested as pesticides against the agriculture pest Helicoverpa armigera. The efficacy tests were performed at different concentrations of AgNPs against the larval stages of $H$. armigera. The mortality was recorded after different time intervals (1-6 days). The $1^{\text {st }}$ and $2^{\text {nd }}$ instar larva has shown the $50-80 \%, 3^{\text {rd }}$ instar $50-70 \%, 4^{\text {th }}$ instar $40-60 \%, 5^{\text {th }}$ instar $50-70 \%$ and $6^{\text {th }}$ instar $70-90 \%$ mortality. This study focussed on the cost effective and eco-friendly bionanoapproach towards the pest control. In future, the AgNPs will be tested for field trials. (C) 2016 iGlobal Research and Publishing Foundation. All rights reserved.
\end{abstract}

Conference Proceedings: International Conference on Advances in Plant and Microbial Biotechnology (PMB-2017); JIIT, Noida: February 02-04, 2017

Indo Global Journal of Pharmaceutical Sciences( ISSN 22491023 ; CODEN- IGJPAI; NLM ID: 101610675) indexed and abstracted in EMBASE(Elsevier), SCIRUS(Elsevier),CABI, CAB Abstracts, Chemical Abstract Services(CAS), American Chemical Society(ACS), Index Copernicus, EBSCO, DOAJ, Google Scholar and many more. For further details, visit http://iglobaljournal.com 